\title{
Jejuno-ileal diverticulitis and renal failure
}

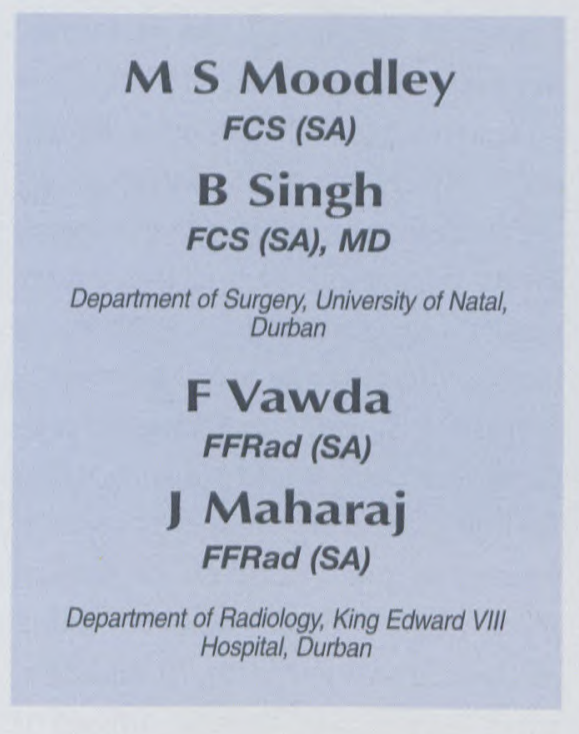

\section{Introduction}

There is increasing awareness that jejuno-ileal diverticulae are more than an interesting incidental finding on radiological contrast studies. A survey of the literature reveals numerous case reports and small series of this pathologic entity presenting in exotic guise. This report adds to these findings; there is no report in the English literature of jejuno-ileal diverticulitis manifesting with profound acute diarrhoea and consequent renal failure.

\section{Case report}

A 69-year-old woman presented with a 2-week history of progressive, severe diarrhoea; she admitted to about eight watery, non-offensive episodes per day. A further complaint was of generalised dull abdominal pain, not colicy in nature. Attempts at outpatient management by her gener- al practitioner were not helpful, hence her presentation to King Edward VIII Hospital, Durban.

Her co-morbid risks included type 2 diabetes and hypertension, both of which were well controlled.

On examination she was noted to be chronically ill-looking and clinically dehydrated. Her general examination was normal, as were her vital signs and temperature. Positive findings were confined to her abdominal assessment, with notable lower abdominal tenderness and watery brown stool on rectal examination.

Admission chest and plain abdominal radiographs were normal. Serum urea and electrolytes were markedly deranged; the serum potassium was $7.1 \mathrm{mmol} / \mathrm{l}$ (normal 3.5 - $5.3 \mathrm{mmol} / \mathrm{l}$ ), urea $55 \mathrm{mmol} / \mathrm{l}$ (normal 3.3 - 6.6 $\mathrm{mmol} / \mathrm{l}$ ) and creatinine $476 \mathrm{mmol} / \mathrm{l}$ (normal 15 - $115 \mathrm{mmol} / \mathrm{l}$ ). Hyperuricaemia resulted in a marked metabolic acidosis with a serum bicarbonate level of $8.5 \mathrm{mmol} / \mathrm{l}$ (nor-

Table I. Serum urea and electrolyte response to fluid and antibiotic therapy

\begin{tabular}{|ccccccr|}
\hline \multicolumn{7}{|c|}{ Table I. Serum urea and electrolyte response to fluid and antibiotic therapy } \\
\hline Day & $\mathbf{N a}$ & $\mathbf{K}$ & $\mathbf{C l}$ & $\mathbf{H C O}_{3}$ & Urea & Creatinine \\
\hline 0 & 127 & 7.1 & 98 & 8.5 & 55.0 & 476 \\
1 & 129 & 4.5 & 109 & 13.8 & 32.4 & 126 \\
3 & 129 & 3.0 & 103 & 17 & 17.0 & 130 \\
5 & 134 & 3.2 & 105 & 15.6 & 15.4 & 158 \\
7 & 136 & 3.9 & 112 & 16.7 & 13.7 & 87 \\
8 & 128 & 3.6 & 106 & 14 & 14.7 & 113 \\
10 & 134 & 3.7 & 113 & 14.3 & 4.8 & 89 \\
Subclassification & & & & & & \\
Na= Sodium; K= potassium; $\mathrm{Cl}=$ chloride; $\mathrm{HCO}_{3}=$ bicarbonate. & & & & \\
\hline
\end{tabular}

$\mathrm{mal} 22$ - $28 \mathrm{mmol} / \mathrm{l})$.

Fluid resuscitation was commenced with normal saline while monitoring central venous pressure and urine output measurements. Response to treatment was prompt and satisfactory and confirmed by improvement in her biochemical profiles as tabulated (Table I).

Investigation of the diarrhoea was simultaneous with her fluid management. The microbiological assessment of the stool did not reveal any pus cells or parasites and culture was negative for pathogenic bacteria.

A barium enema was requested in view of the patient's clinical profile, to exclude a non-benign colonic lesion. For technical reasons related to the diarrhoea, this was not possible. Enteroclysis was undertaken as an imaging alternative; this revealed multiple jejuno-ileal diverticulae, with a predominance in the jejunum (Fig. 1).

The patient was commenced on oral antibiotic therapy (oral neomycin and metronidazole) on day 4 , with satisfactory clinical outcome. The diarrhoea decreased in frequency, and had abated by discharge on day 10 . Abdominal pain also diminished markedly in response to this therapy. A barium enema done subsequently was normal. At 3-month and 6- 


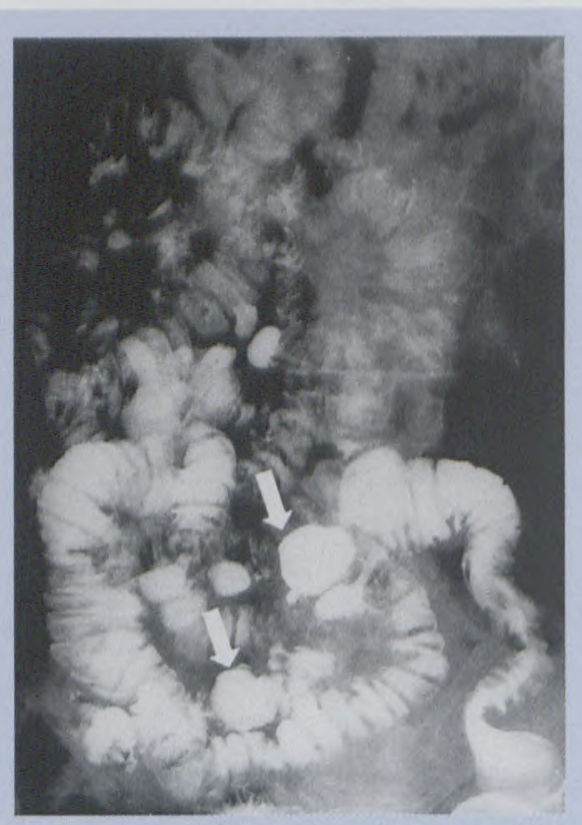

Fig. 1 a. Barium study of the small bowel showing multiple diverticulae predominantly in the jejunum; arrows point to two of the larger ones.

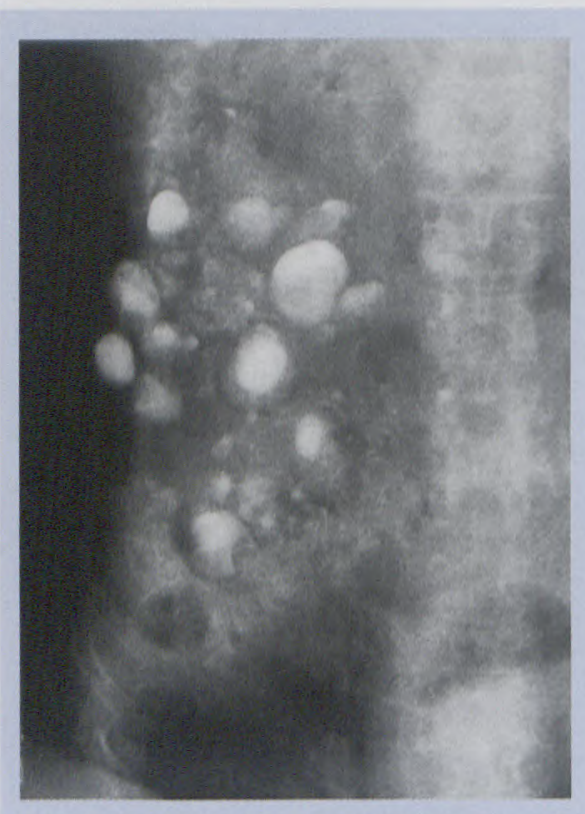

Fig. 1 b. Delayed film from small bowel study showing retention of contrast in multiple diverticulae.

month reviews following discharge the patient was noted to be well.

\section{Discussion}

Primary jejuno-ileal diverticulae are pulsion pseudo-diverticulae that arise on the mesenteric aspect of the bowel at the point of mesenteric vas- cular penetration of the muscularis propria. Aetiologically, like their colonic counterparts, chronic raised intraluminal pressure is implicated on the basis of small bowel dyskinesia and dis-coordinate peristalsis. ${ }^{1}$ Some authors suggest that there may be an associated smooth muscle myopathy. ${ }^{2}$ Jejuno-ileal diverticulae are usually paired and enclosed within mesenteric fat, so masking their presence in the asymptomatic case at laparotomy for some other reason. True incidence is therefore difficult to assess, with reports ranging from $0.25 \%$ to $4.6 \%$ based on radiologic enteroclysis and postmortem pressure distension results. ${ }^{3.4}$ Usually, small bowel diverticulae (SBD) are more common and larger in the proximal jejunum, and decrease in size and number as one progresses down the small bowel; they are found two times more often in males than in females, usually in the sixth and seventh decades of life. Reports of concomitant colonic diverticulae vary from $20 \%$ to $75 \%$ of cases. 3.5

Most cases of jejuno-ileal diverticulae are asymptomatic.

Acutely, patients may present with diverticular abscess, massive haemorrhage, perforation (usually with localised peritonitis), functional or mechanical obstruction, or small

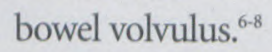

Severe diarrhoea, as in the patient discussed, is not a described form of acute manifestation.

In those patients with less dramatic forms of the disease, symptoms include chronic low-grade gastrointestinal haemorrhage, self-limiting partial obstruction, vague chronic abdominal pain and malabsorption. Steatorrhoea is the result of bile salt deconjugation in an environment of altered bacterial flora. This overgrowth also results in bacterial consumption of vitamin $B_{12}$ with consequent megaloblastic anaemia. ${ }^{6-8}$

Jejuno-ileal diverticulosis has been implicated in the occasional "benign pneumoperitoneum' in patients without peritonitis; this is explained by the passage of air through the permeable mucosa of the thin-walled pouch. ${ }^{3}$

Diagnosing SBD depends largely on the awareness of the pathology by the attending surgeon and radiologist. From a surgical perspective, rarity results in diagnostic delay while more likely differentials are excluded appendicitis, acute cholecystitis, peptic ulcers and colonic diverticulitis. Radiologically, they may be missed if present in small numbers or if large mouthed, resulting in rapid emptying of the contrast medium. In addition, small diverticulae may be missed if inadequate filling pressure is generated at the time of enteroclysis.

Management is supportive in the vast majority of cases, as with colonic diverticulitis. This entails bowel rest, broad-spectrum antibiotics to suppress the bacterial overgrowth, and analgesia. There are reports of prokinetic agent use with good effect in the management of cases of functional obstruction. Usual indications for surgery are perforation and small bowel obstruction. Local resection and anastomosis of the affected segment is entirely satisfactory. Lesser procedures such as excision and simple closure are frowned upon as they are associated with a higher rate of breakdown and fistula formation. ${ }^{5}$

The enigma that is SBD need not be so; a heightened awareness of its existence will result in earlier small bowel imaging, with the obvious benefits of an early diagnosis. Our case 
reveals prompt response to a pathology that would have been difficult to manage had the diagnosis not been made as early as it was, albeit by default.

\section{References}

1. Kongara KR, Soffer EE. Intestinal motility in small bowel diverticulosis: a case report and review of the literature. J Clin Gastroenterol 2000; 30: 84-86.

2. Krisnamurthy S, Kelly MM, Rohrman CA. Jejunal diverticulosis. Gastroenterology 1983; 85: 538-547.

3. Maglinte DDT, Chernish SM, DeWeese R, Kelvin FM, Brunelle RL. Acquired jejunoileal diverticular disease: Subject review. Radiology 1986; 158: 577-580.

4. Alvarez OA, Mejia A, Ostrower VS, Lee M. Jejunal diverticulitis manifesting with abdominal wall abscess. Am J Gastroenterol 1995; 11: 2060-2062.

5. de Bree E, Grammatikakis J, Christodoulakis M, Tsiftsis D. The clinical sig. nificance of acquired jejunoileal diverticula. Am J Gastroenterol 1998; 93: 2523-2528.

6. Rodriguez HE, Ziauddin MF, Quiros ED, Brown AM, Podbielski FJ. Jejunal diverticulosis and gastrointestinal bleeding. J Clin Gastroenterol 2001; 33: 412-414.

7. Zager JS, Garbus JE, Shaw JP, Cohen MG, Garber SM. Jejunal diverticulosis: a rare entity with multiple presentations, a series of cases. Digestive Surgery 2000; 17: 643-645

8. Schwesinger WH, Sirinek KR, Gaskill HV, Velez JP, Corea J, Strodel WE. Jejunoileal causes of overt gastrointestinal bleeding: diagnosis, management and outcome. Am Surg 2001; 67: 383-387.
RADIOGRAPHERS

\section{did you know?}

With Corinth, you can see things

from a different angle while working and living in the UK?

Are you interested?

Consult with Corinth today.

\section{5 years of global}

recruitment experience makes Corinth Healthcare the expert in medical recruitment.

\section{Recruiting for the UK now}

\section{II 20}

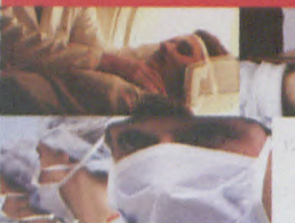

work with us and

we'll work for you

corinth@icon.co.za

www.corinthhealthcare.com

more choice more money more benefits more opportunities more experience

Australia

New Zealand

Canada

South Africa

United Kingdom

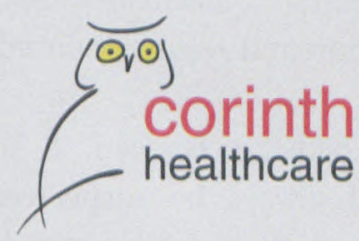

